ГЕОГРАФИЧЕСКАЯ ВАРИАБЕЛЬНОСТЬ СОДЕРЖАНИЯ ТЯЖЕЛЫХ МЕТАЛЛОВ В ТКАНЯХ МЕДИЦИНСКИХ ПИЯВОК (HIRUDO MEDICINALIS, HIRUDO VERBANA) И В ДОННЫХ ОТЛОЖЕНИЯХ ИЗ МЕСТ ИХ ОБИТАНИЯ

\author{
Л. В. Черная ${ }^{1, *}$, Л. А. Ковальчук ${ }^{1}$, Н. В. Микшевич ${ }^{2}$ \\ ${ }^{1}$ Институт экологии растений и животных УрО РАН, Россия \\ ${ }^{2}$ Уральский государственньй педагогический университет, Россия \\ *e-mail:kovalchuk@ipae.uran.ru
}

Поступила: 25.04.2019. Исправлена: 21.05.2019. Принята к опубликованию: 20.06.2019.

\begin{abstract}
Впервые представлены результаты исследования содержания тяжелых металлов $\mathrm{Cu}, \mathrm{Zn}, \mathrm{Mn}, \mathrm{Fe}, \mathrm{Cd}, \mathrm{Pb}$, Ni в тканях двух охраняемых видов медицинских пиявок (Hirudo medicinalis и Hirudo verbana) и в донных отложениях из мест их обитания различных регионов России и Украины. Обнаружено, что географический фактор оказывает существенное влияние на элементный статус медицинских пиявок и донных отложений. Показано, что, независимо от географической и биотопической приуроченности, оба вида медицинских пиявок являются макроконцентраторами $\mathrm{Zn}$ и деконцентраторами $\mathrm{Mn}$ и Fe. Выявлена высокая кумулятивная активность $H$. medicinalis и $H$. verbana по отношению к экотоксикантам $\mathrm{Cd}, \mathrm{Pb}$ и $\mathrm{Ni}$ в водных экосистемах промышленных регионов. Показано снижение биоаккумуляционной активности к тяжелым металлам у особей медицинских пиявок, обитающих в неблагоприятных климатических условиях на северной и восточной границах ареала. Установлена способность пиявок H. medicinalis и H. verbana регулировать уровень эссенциальных металлов $\mathrm{Mn}$ и $\mathrm{Zn}$ в организме, тогда как содержание $\mathrm{Cu}$, $\mathrm{Fe}, \mathrm{Cd}, \mathrm{Pb}, \mathrm{Ni}$ определяется концентрацией этих элементов в среде обитания (донные отложения). На основании полученных данных установлено, что высокая вариабельность изучаемых параметров и общие закономерности биоаккумуляционной активности пиявок H. medicinalis и $H$. verbana по отношению к тяжелым металлам обусловлены как климатогеографическими особенностями изучаемых регионов, так и степенью антропогенной трансформации ландшафтов. Обнаружено, что микроэлементный статус пиявок в целом объективно отражает региональную специфику экологического состояния гидробиоценозов. Полученные данные по фоновым концентрациям тяжелых металлов могут быть целенаправленно использованы для оптимизации мер по сохранению природных популяций медицинских пиявок $H$. теdicinalis и $H$. verbana и восполнению их природных ресурсов, а также как физиологическая норма для пиявок-производителей и их потомства в искусственно созданных условиях на биофабриках.
\end{abstract}

Ключевые слова: биоаккумуляция, водные экосистемы, охраняемые виды, экотоксиканты, эссенциальные металлы

Из шести видов медицинских пиявок (МП), известных для Палеарктики, на территории России и зарубежной Европы обитают два - Hirudo medicinalis Linnaeus, 1758 и Hirudo verbana Carena, 1820 (Лукин, 1976; Utevsky et al., 2010; Saglam et al., 2016). Европейская, или лечебная, МП H. medicinalis распространена в лесной и лесостепной зоне Евразии. В широтном направлении ее ареал простирается более чем на 5700 км от Великобритании на западе до Алтайских гор на востоке. Средиземноморская, или аптечная, пиявка $H$. verbana обитает южнее лечебной пиявки в степной и средиземноморской зоне и протяженность ее ареала с запада на восток - около 4600 км от Испании до Узбекистана. Оба вида МП в настоящее время имеют охраняемый статус. Hirudo medicinalis классифицируется как «находящийся под угрозой исчезновения» таксон в Красном списке МСОП, включенный в приложение III к
Бернской конвенции, приложение II к CITES (Utevsky et al., 2014; CITES, 2017). Hirudo verbana отмечается как «редкий, уязвимый или низкого риска угрозы исчезновения вид» для Украины и отдельных регионов России (Краснодарский край, Республики Крым и Адыгея) (Красная книга Краснодарского края, 2007; Кустов, Шаповалов, 2012; Червона книга України, 2009). В природоохранных документах указаны факторы, лимитирующие численность и распространение МП: массовый вылов в коммерческих целях, загрязнение и уничтожение водоемов, снижение плотности популяции лягушек, служащих источником питания для молодых пиявок, мелиоративные мероприятия, неблагоприятные условия на северной границе ареала. Также предложены меры их охраны: выявление и сохранение биотопов, использование искусственного воспроизводства для восстановления природных популяций. 
В настоящее время МП, широко используемые в медицине, ветеринарии, фармакологии и косметологии (Ковальчук, Черная, 2013; Каменев, Каменев, 2014; Никонов и др., 2015), выращиваются на биофабриках в искусственно созданных условиях, однако современная технология гирудокультуры требует регулярного изъятия половозрелых особей из природных популяций (Лукин, 1976; Рассадина, Романова, 2008; Кустов и др., 2014). Основные запасы природных МП, используемых в качестве маток-производителей на биофабриках, сосредоточены в водных экосистемах Юга России, Закавказья и Турции (H. verbana), в Украине и Молдавии (H. medicinalis), где еще наблюдается их высокая численность. Однако, несмотря на то, что на фармацевтический рынок поступают сертифицированные МП из гирудокультуры, значительного восстановления их природных популяций на большей части ареалов не происходит. Это обусловлено, помимо браконьерского перепромысла, усиливающейся антропогенной нагрузкой на пресноводные экосистемы, приобретающей в последние десятилетия глобальный характер (Elliot \& Kutschera, 2011; Saglam et al., 2016). Известно, что МП весьма чувствительны к химическому загрязнению водной среды и являются биоиндикаторами экологической чистоты водоемов (Romanenko et al., 2010; Романова, Климина, 2010), в том числе и на наличие таких поллютантов, как тяжелые металлы (ТМ), входящих в число приоритетных (Флеров, 1989; Нохрина и др., 2009).

К настоящему времени в научной литературе практически отсутствуют сведения об элементном статусе медицинских пиявок из природных популяций, тем более в географическом аспекте. А их аккумуляционные особенности по отношению к ТМ, изучены недостаточно полно. Вместе с тем, мероприятия по сохранению МП и восполнению их природных ресурсов должны, несомненно, включать, наряду со всеми прочими, и комплексную оценку антропогенной трансформации мест их обитания. И особенно важно определение фонового уровня содержания ТМ в организме пиявок в отдельных регионах ареала, отличающихся большим разнообразием геохимических и климатических условий.

Актуальность данной проблемы и определила цель нашего исследования - изучение географических особенностей содержания тяжелых металлов в тканях $H$. medicinalis и $H$. verbana и в донных отложениях из мест их обитания.

\section{Материал и методы}

В исследованиях использованы взрослые особи двух видов медицинских пиявок из природных популяций различных регионов России и Украины. Пиявки H. medicinalis отловлены в пяти водоемах: p. Лесной Воронеж (Тамбовская область, $52.63^{\circ} \mathrm{N} ; 40.25^{\circ} \mathrm{E}$, лесостепная зона, среднегодовая температура $+6.1^{\circ} \mathrm{C}$ ), озеро Горелое (Харьковская область $1,49.62^{\circ} \mathrm{N} ; 36.51^{\circ} \mathrm{E}$, лесостепь, $+8.1^{\circ} \mathrm{C}$ ), река Уды (Харьковская область $2,49.78^{\circ} \mathrm{N} ; 36.30^{\circ} \mathrm{E}$, лесостепь, $\left.+8.1^{\circ} \mathrm{C}\right)$, озеро Глубокое (Луганский национальный заповедник, Луганская область, $48.67^{\circ} \mathrm{N} ; 39.47^{\circ} \mathrm{E}$, лесостепь, $+8.5^{\circ} \mathrm{C}$ ), озеро Дамба (Алтайский край, $53.35^{\circ} \mathrm{N} ; 84.63^{\circ} \mathrm{E}$, южная тайга, $\left.+2.6^{\circ} \mathrm{C}\right)$. Особи $H$. verbana отловлены в трех водоемах: оз. Горелое, ерик Судомойка (Волгоградская область, $48.58^{\circ} \mathrm{N} ; 45.03^{\circ} \mathrm{E}$, степь, $\left.+8.8^{\circ} \mathrm{C}\right)$, река Челбас (Краснодарский край, $46.07^{\circ} \mathrm{N} ; 38.97^{\circ} \mathrm{E}$, степь, $\left.+11.9^{\circ} \mathrm{C}\right)$. Исследуемые водные объекты были приняты как фоновые, поскольку они располагаются на значительном удалении от крупных населенных пунктов и не подвергаются прямому воздействию поллютантов.

Пиявок отлавливали с помощью гидробиологического сачка в весенний период (апрель - май, 2009-2012 гг.), в дневное время, в литоральной части водоемов на глубине 50-100 см. Одновременно проводили отбор донных отложений (ДО) согласно ГОСТ 17.1.5.01-80 цилиндрическим пробоотборником из верхнего (10 см) слоя дна в герметичные стеклянные сосуды (500 мл). До начала анализа пробы хранили при $-16^{\circ} \mathrm{C}$. Отлов и содержание животных, доставленных в лабораторию, осуществляли в соответствии с правилами, принятыми Европейской Конвенцией по защите животных, используемых для экспериментальных и научных целей.

Пробы ДО и кожно-мышечной ткани пиявок готовили способом «мокрой» минерализации высушенных образцов в смеси азотной $\left(\mathrm{HNO}_{3}\right)$ и хлорной $\left(\mathrm{HClO}_{4}\right)$ кислот. Валовое содержание $\mathrm{Cu}, \mathrm{Zn}, \mathrm{Fe}, \mathrm{Mn}, \mathrm{Cd}, \mathrm{Pb}$, Ni в пробах определяли атомно-абсорбционным методом на спектрофотометре AAS-3 (основная погрешность по оптической плотности не превышает $\pm 5 \%$ от диапазона измерения) в пламени пропан-бутан и на приборе Analyst 100 фирмы Perkin Elmer (Другов, Родин, 2009). Концентрацию 
металлов выражали в мкг/г воздушно-сухой массы. Подготовлено и проанализировано 150 проб, проведено 1050 элементо-определений.

Закономерности биологической аккумуляции ТМ пиявками оценивали с помощью коэффициента биологического накопления $\left(\mathrm{K}_{\text {Бн }}\right)$, рассчитанного по отношению средних значений тканевых концентраций ТМ к их концентрациям в ДО. По характеру и степени кумуляционных способностей гидробионтов принято разделять на три группы: макроконцентраторы $\left(\mathrm{K}_{\mathrm{bH}}>2\right)$, микроконцентраторы $\left(\mathrm{K}_{\mathrm{bH}}\right.$ от 1 до 2) и деконцентраторы $\left(\mathrm{K}_{\mathrm{БH}}<1\right)$ (Никаноров и др., 1993; Яковлев, 2002).

Экспериментальные данные обрабатывали с использованием пакета лицензионных прикладных программ «Statistica v. 7.0.» (Stat Soft, Ink.). При множественном и парном сравнении групп, проведенном с помощью $F$-критерия Фишера и Тьюки-теста (ANOVA, post-hoc, Tukey HSD test), данные преобразовывали в логарифмическую форму. Для оценки связи между изучаемыми параметрами использовали корреляционный анализ Спирмена $\left(\mathrm{r}_{\mathrm{s}}\right)$. Метод главных компонент (РСА) проведен с помощью статистической среды R (R 3.1.2, пакеты «Vegan» и «Ade4») (Chessel et al., 2004). Различия между сравниваемыми выборками считали статистически значимыми при $p<0.05$.

\section{Результаты и обсуждение}

Для медицинских пиявок ДО представляют собой основную среду обитания, являются важнейшей составляющей биоценоза. Химический состав ДО определяет степень аккумуляции ТМ и во многом регулирует микроэлементный обмен. Обладая не только высокой аккумулирующей способностью по отношению к ТМ, но и свойством «памяти», ДО отражают экологическое состояние биотопа за достаточно продолжительный период времени (Stumm \& Morgan, 1996; Степанова и др.,
2007). В настоящее время в Российской Федерации не определены нормативы содержания ТМ в ДО. Отсутствуют универсальные методы, позволяющие устанавливать критерии качества ДО, которые могли бы быть полезны для охраны водных и биологических ресурсов в региональном масштабе. На сегодня наиболее распространенный подход заключается в сравнении полученных валовых концентраций ТМ со значением величин кларка литосферы, региональными фоновыми концентрациями или ранее полученными натурными данными.

Результаты наших исследований показали, что, за исключением $\mathrm{Cd}$, концентрации всех изучаемых ТМ в ДО рассматриваемых водоемов значительно ниже их кларков по Виноградову (1962) и соответствуют показателям, указанным для фоновых водоемов европейской части бывшего СССР (Никаноров и др., 1993 ) (табл. 1, табл. 2).

Отмечено незначительное превышение фоновой концентрации $\mathrm{Cd}$ в ДО Луганской и Волгоградской областей, Краснодарского края. Это согласуется с литературными данными о высоком уровне накопления $\mathrm{Cd}$ за последние десятилетия в абиотических и биотических компонентах водных экосистем не только на загрязненных, но и на фоновых территориях. Последнее обусловлено глобальным характером техногенного загрязнения окружающей среды (Степанова и др., 2007; Моисеенко, 2009; Kovalchuk et al., 2017; Решетняк и др., 2017).

Концентрации ТМ в ДО исследуемых водных объектов, независимо от географического положения, располагаются в единой последовательности: $\mathrm{Fe}>\mathrm{Mn}>\mathrm{Zn}>\mathrm{Ni}>\mathrm{Pb} \geq \mathrm{Cu}$ $>\mathrm{Cd}$. В то же время исследованные водоемы характеризуются значительной вариабельностью концентрации ТМ, что обусловлено разнообразием природных условий и степенью антропогенной трансформации ландшафтов в изучаемых регионах (табл. 2).

Таблица 1. Концентрации тяжелых металлов (мкг/г сухого вещества) в донных отложениях фоновых водных объектов и их кларк в литосфере

Table 1. Concentrations of heavy metals ( $\mu \mathrm{g} / \mathrm{g}$ dry matter) in bottom sediments of background water bodies of the European part of the former USSR and their clarks in the lithosphere

\begin{tabular}{|c|c|c|c|c|c|c|}
\hline $\mathrm{Cu}$ & $\mathrm{Zn}$ & $\mathrm{Mn}$ & $\mathrm{Fe}$ & $\mathrm{Cd}$ & $\mathrm{Pb}$ & $\mathrm{Ni}$ \\
\hline \multicolumn{7}{|c|}{ Фоновые водные объекты (Никаноров и др., 1993) } \\
\hline $4-50$ & $8-60$ & $70-400$ & $11000-18000$ & $0.1-1.2$ & $5-18$ & $0.9-15$ \\
\hline \multicolumn{7}{|c|}{ Кларк земной коры (Виноградов, 1962) } \\
\hline 47 & 83 & 1000 & 46500 & 0.13 & 16 & 58 \\
\hline
\end{tabular}


Таблица 2. Валовое содержание тяжелых металлов (мкг/г сухого вещества) в донных отложениях водных экосистем различных регионов

Table 2. The total content of heavy metals $(\mu \mathrm{g} / \mathrm{g}$ dry matter) in the sediments aquatic ecosystems in different regions

\begin{tabular}{|c|c|c|c|c|c|c|c|}
\hline \multirow{2}{*}{ Показатель } & \multicolumn{7}{|c|}{ Тяжелые металлы } \\
\hline & $\mathrm{Cu}$ & $\mathrm{Zn}$ & $\mathrm{Mn}$ & $\mathrm{Fe}$ & $\mathrm{Cd}$ & $\mathrm{Pb}$ & $\mathrm{Ni}$ \\
\hline \multicolumn{8}{|c|}{ 1. p. Лесной Воронеж, Тамбовская область $(\mathrm{n}=10)$} \\
\hline$M$ & 4.64 & $30.73^{2,3,4}$ & $68.46^{2,5}$ & 1418.4 & 0.92 & $5.94^{2}$ & 7.63 \\
\hline$m$ & 0.03 & 0.42 & 1.25 & 17.08 & 0.03 & 0.04 & 0.07 \\
\hline $\min$ & 4.49 & 28.9 & 62.6 & 1398.4 & 0.87 & 5.74 & 7.39 \\
\hline $\max$ & 4.78 & 32.6 & 74.1 & 1453.3 & 1.04 & 6.18 & 8.06 \\
\hline \multicolumn{8}{|c|}{ 2. оз. Горелое, Харьковская область $1(\mathrm{n}=10)$} \\
\hline$M$ & $5.06^{6}$ & $32.72^{1,3}$ & $69.63^{1,5}$ & 9169.4 & 1.06 & $6.26^{1,6}$ & $10.52^{6}$ \\
\hline$m$ & 0.08 & 2.02 & 2.43 & 34.1 & 0.02 & 0.22 & 0.69 \\
\hline $\min$ & 4.81 & 26.90 & 59.30 & 9001.5 & 1.01 & 5.62 & 8.51 \\
\hline $\max$ & 5.32 & 38.58 & 79.69 & 9348.9 & 1.12 & 6.89 & 12.55 \\
\hline \multicolumn{8}{|c|}{ 3. p. Уды, Харьковская область $2(\mathrm{n}=10)$} \\
\hline$M$ & 8.05 & $28.50^{1,2}$ & $80.84^{5}$ & 12187.2 & $1.25^{7}$ & 8.46 & $12.52^{4}$ \\
\hline$m$ & 0.13 & 2.52 & 3.11 & 94.16 & 0.02 & 0.06 & 0.08 \\
\hline $\min$ & 7.51 & 17.90 & 69.10 & 11794.8 & 1.16 & 8.19 & 12.11 \\
\hline $\max$ & 8.61 & 39.09 & 93.22 & 12588.3 & 1.32 & 8.74 & 12.87 \\
\hline \multicolumn{8}{|c|}{ 4. о3. Глубокое, Луганская область $(\mathrm{n}=10)$} \\
\hline$M$ & 6.15 & $37.83^{1,2,5}$ & 38.27 & 11680.1 & $1.66^{5}$ & $6.94^{5,6}$ & $14.40^{3,5}$ \\
\hline$m$ & 0.14 & 2.97 & 3.35 & 71.49 & 0.03 & 0.02 & 0.75 \\
\hline $\min$ & 5.78 & 29.04 & 28.18 & 11254.1 & 1.56 & 6.85 & 12.04 \\
\hline $\max$ & 6.53 & 47.74 & 49.14 & 11965.7 & 1.76 & 7.04 & 16.51 \\
\hline \multicolumn{8}{|c|}{ 5. ер. Судомойка, Волгоградская область $(\mathrm{n}=10)$} \\
\hline$M$ & 7.07 & $43.06^{4}$ & $74.09^{1,2,3}$ & 5881.0 & $1.72^{4}$ & $7.15^{4}$ & $15.60^{4}$ \\
\hline$m$ & 0.05 & 2.43 & 2.76 & 70.68 & 0.02 & 0.04 & 1.19 \\
\hline $\min$ & 6.84 & 31.90 & 63.90 & 5521.7 & 1.62 & 6.94 & 10.78 \\
\hline $\max$ & 7.32 & 53.13 & 85.04 & 6185.0 & 1.83 & 7.39 & 20.63 \\
\hline \multicolumn{8}{|c|}{ 6. p. Челбас, Краснодарский край $(\mathrm{n}=10)$} \\
\hline$M$ & $5.14^{2}$ & 23.12 & 181.93 & 4751.4 & 1.46 & $6.50^{2,4}$ & $9.45^{2}$ \\
\hline$m$ & 0.03 & 0.08 & 3.25 & 17.93 & 0.02 & 0.10 & 0.24 \\
\hline $\min$ & 4.98 & 22.73 & 166.68 & 4658.1 & 1.38 & 6.15 & 8.84 \\
\hline $\max$ & 5.29 & 23.50 & 197.31 & 4849.9 & 1.54 & 7.08 & 10.15 \\
\hline \multicolumn{8}{|c|}{ 7. оз. Дамба, Алтайский край $(\mathrm{n}=10)$} \\
\hline$M$ & 15.48 & 76.84 & 281.40 & 17245.8 & $1.23^{3}$ & 15.48 & 22.53 \\
\hline$m$ & 0.20 & 1.15 & 2.98 & 62.07 & 0.01 & 0.46 & 0.75 \\
\hline $\min$ & 14.60 & 71.70 & 268.00 & 16920.0 & 1.16 & 13.60 & 19.70 \\
\hline $\max$ & 16.36 & 82.31 & 294.92 & 17574.0 & 1.29 & 17.68 & 25.86 \\
\hline \multicolumn{8}{|c|}{$\operatorname{ANOVA}(\mathrm{n}=70)$} \\
\hline$F_{60}$ & 1368.5 & 63.48 & 386.90 & 1629.6 & 275.16 & 420.68 & 79.98 \\
\hline$p$ & 0.000 & 0.004 & 0.000 & 0.000 & 0.000 & 0.000 & 0.000 \\
\hline
\end{tabular}

Примечание: $M$ - среднее арифметическое; $m$ - ошибка среднего арифметического; $\min$ и $\max$ - минимальное и максимальное значение концентрации; ANOVA - однофакторный дисперсионный анализ; $F$ - критерий Фишера; надстрочными цифрами обозначены номера регионов, между которыми отсутствуют статистически значимые различия (Tukey HSD test, $p>0.05$ ).

Наибольшая географическая изменчивость грунтовых концентраций выявлена для $\mathrm{Fe}(p=$ $0.000)$, наименьшая - для Zn $(p=0.004)$. Отмечено, что в озере Дамба (Алтайский край) концентрации практически всех изучаемых ТМ в ДО, за исключением $\mathrm{Cd}$, существенно выше, чем в изучаемых нами водоемах европейских регионов $(p=0.001)$. В юго-западной части Алтайского края, где проводились наши исследования, имеются многочисленные рудопроявления и ореолы рассеяния полиметаллов, разрабатывается ряд месторождений, отмечается повышенное содержание $\mathrm{Cu}, \mathrm{Zn}, \mathrm{Pb}$ и $\mathrm{Cd}$ в объектах окружающей среды (Рождественская, 2003). Кроме того, загрязняющие вещества поступают в регион посредством трансграничного переноса от инду- стриальных центров сопредельных территорий Казахстана и Кузбасса (Ковалев и др., 1993). В изученных нами водоемах Украины и европейской части России также можно выделить случаи повышения концентрации ТМ, связанные с геохимическими особенностями и промышленной спецификой регионов (Еськов и др., 2015; Lukashov, 2015; Yorkina, 2016). Так, высокое содержание $\mathrm{Fe}$ наблюдается в ДО водных экосистем Украины, Mn - в Краснодарском крае, Ni и $\mathrm{Cd}$ - в Волгоградской и Луганской областях.

Показано, что географический фактор оказывает существенное влияние на микроэлементный статус медицинских пиявок. В тканях $H$. medicinalis установлено изменение содержания $\mathrm{Cu}, \mathrm{Zn}$, $\mathrm{Mn}, \mathrm{Fe}, \mathrm{Cd}, \mathrm{Pb}, \mathrm{Ni}$ в широком диапазоне (табл. 3). 
Таблица 3. Валовое содержание тяжелых металлов (мкг/г сухого вещества) в тканях Hirudo medicinalis из водных экосистем различных регионов

Table 3. The total content of heavy metals ( $\mu \mathrm{g} / \mathrm{g}$ dry matter) in the tissues of Hirudo medicinalis from the aquatic ecosystems in different regions

\begin{tabular}{|c|c|c|c|c|c|c|c|}
\hline \multirow{2}{*}{ Показатель } & \multicolumn{7}{|c|}{ Тяжелые металлы } \\
\hline & $\mathrm{Cu}$ & $\mathrm{Zn}$ & $\mathrm{Mn}$ & $\mathrm{Fe}$ & $\mathrm{Cd}$ & $\mathrm{Pb}$ & $\mathrm{Ni}$ \\
\hline \multicolumn{8}{|c|}{ 1. p. Лесной Воронеж, Тамбовская область $(\mathrm{n}=10)$} \\
\hline$M$ & 2.21 & 272.90 & 4.11 & 1037.32 & 0.12 & 0.92 & 0.98 \\
\hline$m$ & 0.09 & 10.27 & 0.07 & 22.99 & 0.01 & 0.04 & 0.05 \\
\hline $\min$ & 1.81 & 225.93 & 3.81 & 916.70 & 0.09 & 0.78 & 0.77 \\
\hline $\max$ & 2.54 & 321.26 & 4.40 & 1136.65 & 0.17 & 1.31 & 1.22 \\
\hline \multicolumn{8}{|c|}{ 2. оз. Горелое, Харьковская область $1(\mathrm{n}=10)$} \\
\hline$M$ & 14.51 & $364.09^{4}$ & $20.70^{3}$ & 3799.52 & 2.73 & $13.52^{5}$ & 13.46 \\
\hline$m$ & 0.75 & 4.48 & 1.11 & 48.90 & 0.03 & 0.41 & 0.50 \\
\hline $\min$ & 11.20 & 344.20 & 15.70 & 3560.10 & 2.61 & 11.70 & 11.50 \\
\hline $\max$ & 17.47 & 384.41 & 25.65 & 4041.31 & 2.86 & 15.35 & 15.47 \\
\hline \multicolumn{8}{|c|}{ 3. p. Уды, Харьковская область $2(\mathrm{n}=10)$} \\
\hline$M$ & 22.49 & 426.34 & $22.57^{2,4}$ & 2367.70 & $4.15^{5}$ & $22.53^{4}$ & $16.56^{5}$ \\
\hline$m$ & 1.38 & 5.09 & 1.41 & 49.69 & 0.03 & 1.22 & 0.41 \\
\hline $\min$ & 16.70 & 401.10 & 16.50 & 2149.80 & 3.98 & 17.40 & 14.90 \\
\hline $\max$ & 28.68 & 448.64 & 28.67 & 2589.94 & 4.29 & 27.37 & 18.58 \\
\hline \multicolumn{8}{|c|}{ 4. оз. Глубокое, Луганская область $(\mathrm{n}=10)$} \\
\hline$M$ & 27.18 & $344.07^{2}$ & $24.49^{3}$ & 4384.98 & 13.18 & $23.62^{3}$ & 42.41 \\
\hline$m$ & 0.58 & 13.50 & 0.92 & 46.18 & 0.95 & 0.48 & 1.69 \\
\hline $\min$ & 24.91 & 281.71 & 19.67 & 4189.60 & 9.81 & 20.79 & 36.80 \\
\hline $\max$ & 30.39 & 369.43 & 27.61 & 4592.17 & 17.97 & 25.35 & 52.22 \\
\hline \multicolumn{8}{|c|}{ 5. оз. Дамба, Алтайский край $(\mathrm{n}=10)$} \\
\hline$M$ & 10.43 & 669.59 & 5.83 & 1427.70 & $3.95^{3}$ & $13.85^{2}$ & $16.42^{3}$ \\
\hline$m$ & 0.23 & 4.56 & 0.21 & 13.94 & 0.05 & 0.24 & 0.23 \\
\hline $\min$ & 9.61 & 649.20 & 4.92 & 1360.00 & 3.72 & 12.69 & 15.31 \\
\hline $\max$ & 11.62 & 694.07 & 6.87 & 1494.80 & 4.19 & 14.95 & 17.37 \\
\hline \multicolumn{8}{|c|}{$\operatorname{ANOVA}(\mathrm{n}=50)$} \\
\hline$F_{4,4} 5$ & 475.12 & 166.58 & 322.93 & 1445.0 & 894.35 & 1182.0 & 1578.0 \\
\hline$p$ & 0.000 & 0.001 & 0.000 & 0.000 & 0.000 & 0.000 & 0.000 \\
\hline
\end{tabular}

Примечание: $M$ - среднее арифметическое; $m$ - ошибка среднего арифметического; $\min$ и тах - минимальное и максимальное значение концентрации; ANOVA - однофакторный дисперсионный анализ; $F$ - критерий Фишера; надстрочными цифрами обозначены номера регионов, между которыми отсутствуют статистически значимые различия (Tukey HSD test, $p>0.05$ ).

Наибольшая географическая вариабельность концентраций характерна для $\mathrm{Fe}, \mathrm{Ni}$ и $\mathrm{Pb}$ $(p=0.000)$, наименьшая - для Zn $(p=0.001)$.

Минимальное содержание всех ТМ выявлено в тканях особей $H$. medicinalis из р. Лесной Воронеж, протекающей по сельскохозяйственно освоенной территории Тамбовской области, на северной окраине ареала $(p=0.000)$. Ткани особей алтайской популяции вида характеризуются высокими содержаниями $\mathrm{Zn}(p=0.000)$, а максимальное содержание $\mathrm{Cu}, \mathrm{Fe}, \mathrm{Cd}$, Ni отмечено в тканях пиявок, обитающих на территории промышленного Донбасса (оз. Глубокое, Луганская обл.) $(p<0.01)$. Для $\mathrm{Mn}$ и $\mathrm{Pb}$ характерны значимо высокие (относительно особей других популяций) концентрации в тканях пиявок из водоемов восточной части Украины (оз. Глубокое и р. Уды) $(p<0.001)$. Это согласуется с литературными данными о существенном превышении фоновых показателей ТМ в тканях гидробионтов в этих регионах (Lukashov, 2015). Следует особо подчеркнуть, что оз. Глубокое расположено в природоохранной зоне Луганского национального заповедника, где отсутствуют источники прямого поступления поллютантов в водную среду. И выявленный нами повышенный уровень ТМ в абиотической и биотической компонентах обусловлен атмосферным переносом.

Использование анализа главных компонент (РCA) позволило визуализировать географические различия элементного спектра тканей медицинских пиявок $H$. medicinalis: $69.80 \%$ общей дисперсии приходится на первую главную компоненту (РС 1), 17.68\% - на вторую главную компоненту (РС 2) (рис. 1).

Как видно из рис. 1, все экспериментальные наблюдения оформились в пять региональных групп пиявок. При этом отмечена существенная пространственная дифференциация географических популяций, обитающих на восточной и северной границах ареала (Алтайский край и Тамбовская область), для которых характерны пониженное содержание $\mathrm{Cu}, \mathrm{Fe}, \mathrm{Mn}, \mathrm{Cd}, \mathrm{Pb}, \mathrm{Ni}$ в тканях, а также высокие концентрации Zn у алтайских особей $H$. medicinalis. Наибольший вклад в географическую изменчивость ТМ по РС1 вносят Сu (18.95\%) и Ni (17.37\%), по РC2 - Zn (76.42\%), а их коэффициенты корреляции с главными компонентами составляют 0.96, 0.92 и -0.97, соответственно ( $p=0.000)$.

При сравнительном анализе микроэлементного состава тканей другого вида медицинских пия- 
вок H. verbana также были выявлены существенные популяционные различия (табл. 4).

Наибольшая географическая вариабельность тканевых концентраций характерна, как и у H. medicinalis, для $\mathrm{Fe}$ и $\mathrm{Ni}$, а также для $\mathrm{Mn}$ и $\mathrm{Cd}(p=0.000)$, наименьшая - для $\mathrm{Zn}(p=0.01)$. Максимальные концентрации токсичных металлов $\mathrm{Cd}$ и $\mathrm{Ni}(p=0.000)$, и минимальные - эссенциальных $\mathrm{Zn}, \mathrm{Mn}, \mathrm{Fe}(p<0.01)$ обнаружены в тканях пиявок из водоема индустриально развитого региона (ер. Судомойка, Волгоградская область). Обратная картина характерна для особей $H$. verbana, обитающих также на промышленной территории на северной границе ареала (оз. Горелое, Харьковская область 1): максимальные тканевые концентрации $\mathrm{Mn}, \mathrm{Fe}$ $(p<0.01)$ и минимальные $-\mathrm{Cd}, \mathrm{Pb}(p=0.000)$.

Методом главных компонент установлена, как и для H. medicinalis, четкая дифференциация трех географических популяций $H$. verbana по уровню содержания ТМ в тканях (рис. 2). На первую главную компоненту (PC1) приходится $54.36 \%$ общей дисперсии, на вторую главную компоненту (РС2) $-18.82 \%$. На рис. 2 отражено повышенное содержание эссенциальных металлов $\mathrm{Fe}, \mathrm{Mn}, \mathrm{Zn}$ и пониженное - экотоксикантов $\mathrm{Cd}$ и $\mathrm{Pb}$ в тканях особей $H$. verbana, обитающих в неблагоприятных климатических условиях се- верной границы ареала (Харьковская область). Отмечена обратная тенденция для пиявок из индустриального региона (Волгоградская область). Наибольший вклад в географические различия по первой компоненте вносят $\mathrm{Cd}(23.54 \%)$ и $\mathrm{Fe}(22.01 \%)$, их коэффициенты корреляции с PC1 составили 0.95 и -0.92, соответственно ( $p=$ $0.000)$. С РС2 сильно коррелируют $\mathrm{Cu}(0.76)$ и $\mathrm{Ni}$ $(0.74)$ ( $p=0.000)$, пониженные концентрации которых выявлены у МП из Краснодарского края. Их вклад в вариабельность ТМ составил $43.74 \%$ и $41.24 \%$, соответственно.

Согласно нашим данным, пиявки $H$. medicinalis, независимо от места обитания, являются макроконцентраторами $\mathrm{Zn}\left(\mathrm{K}_{\mathrm{bH}}>2\right)$ и деконцентраторами $\mathrm{Mn}$ и $\mathrm{Fe}\left(\mathrm{K}_{\mathrm{bH}}<1\right)$ (табл. 5). Выявлена неоднозначная кумулятивная способность к ТМ у МП различных географических популяций. Так, пиявки из Тамбовской области отличаются от особей $H$. medicinalis остальных регионов наибольшей аккумуляционной активностью к $\mathrm{Fe}$ и наименьшей - к $\mathrm{Cu}, \mathrm{Cd}, \mathrm{Pb}, \mathrm{Ni}$, по отношению к которым они являются деконцентраторами $\left(\mathrm{K}_{\mathrm{БH}}<\right.$ 1). Для МП из р. Уды (Харьковская область 2) характерна наибольшая аккумуляция Zn. У особей H. medicinalis из заповедного оз. Глубокое (Луганская область) выявлена самая высокая кумулирующая способность к $\mathrm{Cu}, \mathrm{Mn}, \mathrm{Cd}, \mathrm{Pb}$ и $\mathrm{Ni}$.

Таблица 4. Валовое содержание тяжелых металлов (мкг/г сухого вещества) в тканях Hirudo verbana из водных экосистем различных регионов

Table 4. The total content of heavy metals ( $\mu \mathrm{g} / \mathrm{g}$ dry matter) in the tissues of Hirudo verbana from the aquatic ecosystems in different regions

\begin{tabular}{|c|c|c|c|c|c|c|c|}
\hline \multirow{2}{*}{ Показатель } & \multicolumn{7}{|c|}{ Тяжелые металлы } \\
\hline & $\mathrm{Cu}$ & $\mathrm{Zn}$ & $\mathrm{Mn}$ & $\mathrm{Fe}$ & $\mathrm{Cd}$ & $\mathrm{Pb}$ & $\mathrm{Ni}$ \\
\hline \multicolumn{8}{|c|}{ 1. оз. Горелое, Харьковская область 1 (n = 10) } \\
\hline$M$ & $12.37^{2,3}$ & $412.69^{3}$ & 20.52 & 4055.69 & 2.94 & 14.15 & 15.04 \\
\hline$m$ & 0.46 & 5.63 & 1.22 & 53.94 & 0.05 & 0.31 & 0.17 \\
\hline $\min$ & 10.51 & 388.91 & 15.82 & 3821.63 & 2.69 & 12.91 & 14.22 \\
\hline $\max$ & 14.34 & 436.72 & 25.65 & 4293.81 & 3.15 & 15.45 & 15.76 \\
\hline \multicolumn{8}{|c|}{ 2. ер. Судомойка, Волгоградская область $(\mathrm{n}=10)$} \\
\hline$M$ & $13.47^{1}$ & $309.61^{3}$ & 9.27 & 3085.51 & 6.75 & $17.38^{3}$ & 20.66 \\
\hline$m$ & 0.51 & 25.48 & 0.12 & 41.91 & 0.05 & 0.48 & 1.13 \\
\hline $\min$ & 11.33 & 158.21 & 8.71 & 2874.30 & 6.53 & 15.51 & 15.70 \\
\hline $\max$ & 15.45 & 371.07 & 9.82 & 3236.65 & 7.01 & 19.59 & 25.86 \\
\hline \multicolumn{8}{|c|}{ 3. p. Челбас, Краснодарский край $(\mathrm{n}=10)$} \\
\hline$M$ & $11.11^{1}$ & $371.47^{1,2}$ & 11.99 & 3435.27 & 4.71 & $16.83^{2}$ & 9.21 \\
\hline$m$ & 0.45 & 25.61 & 0.25 & 14.37 & 0.23 & 0.61 & 0.25 \\
\hline $\min$ & 8.83 & 293.33 & 10.89 & 3370.40 & 3.51 & 13.62 & 8.39 \\
\hline $\max$ & 12.62 & 517.52 & 13.34 & 3519.95 & 5.66 & 19.11 & 10.61 \\
\hline \multicolumn{8}{|c|}{ ANOVA $(n=30)$} \\
\hline$F_{2,27}$ & 6.19 & 5.43 & 108.86 & 148.74 & 176.36 & 13.55 & 120.26 \\
\hline$p$ & 0.006 & 0.01 & 0.000 & 0.000 & 0.000 & 0.001 & 0.000 \\
\hline
\end{tabular}

Примечание: $M$ - среднее арифметическое; $m$ - ошибка среднего арифметического; $\min$ и $\operatorname{max~-~минимальное~и~максимальное~}$ значение концентрации; ANOVA - однофакторный дисперсионный анализ; $F$ - критерий Фишера; надстрочными цифрами обозначены номера регионов, между которыми отсутствуют статистически значимые различия (Tukey HSD test, $p>0.05$ ). 


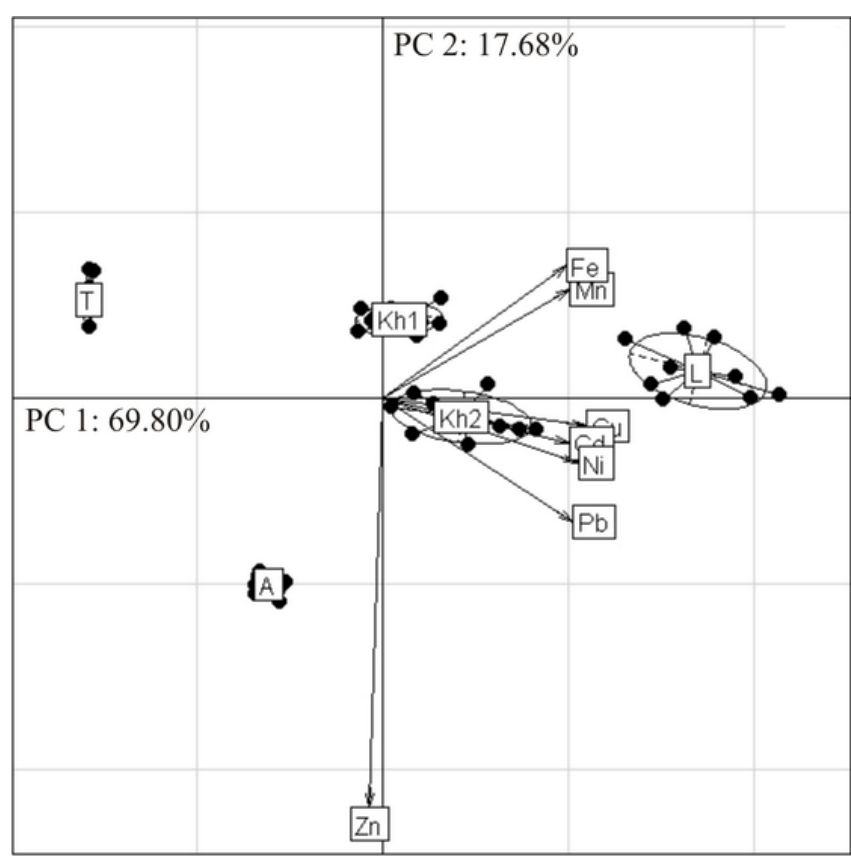

Рис. 1. Содержание тяжелых металлов в тканях Hirudo medicinalis в пространстве главных компонент. Условные обозначения: Т - Тамбовская область, Kh1 - Харьковская область 1, Kh2 - Харьковская область 2, L - Луганская область, А - Алтайский край; РC1, РС2 - оси главных компонент, \% - процент дисперсии данных, объясненных главной компонентой стрелки отражают корреляцию главных компонент с исходными показателями; эллипсы представляют собой 95\% доверительные области. Fig. 1. The content of heavy metals in the tissues of Hirudo medicinalis in the space of the main components. Designations: T - Tambov region, Kh1 - Kharkiv region 1, Kh2 Kharkiv region 2, L - Lugansk region, A - Altaisky Krai; PC1, PC2 - principal component axes; \% - the percentage of the data variance explained by the main components; arrows reflect the correlation of the main components with the initial indicators; ellipses are $95 \%$ confidence areas.

Обратная картина наблюдается у пиявок из алтайского водоема, в котором было отмечено повышенное содержание ТМ в ДО: показатели $\mathrm{K}_{\text {Бн }}$, практически для всех ТМ, за исключением $\mathrm{Cd}$, более низкие, чем у европейских МП. Уровень биоаккумуляции $\mathrm{Cu}, \mathrm{Zn}, \mathrm{Mn}, \mathrm{Ni}, \mathrm{Pb}$ алтайских особей, обитающих в неблагоприятных климатических условиях (короткий безморозный период, суровые зимы, глубокое промерзание грунта), на восточной границе ареала, сопоставим только с накопительными способностями пиявок из близкой по географической широте тамбовской популяции (северная окраина ареала). Низкой кумулятивной активности сибирских пиявок способствует, в первую очередь, более слабая и менее продолжительная прогреваемость воды в силу климатических особенностей региона, поскольку общеизвестно, что интенсивность накопления ТМ напрямую свя-

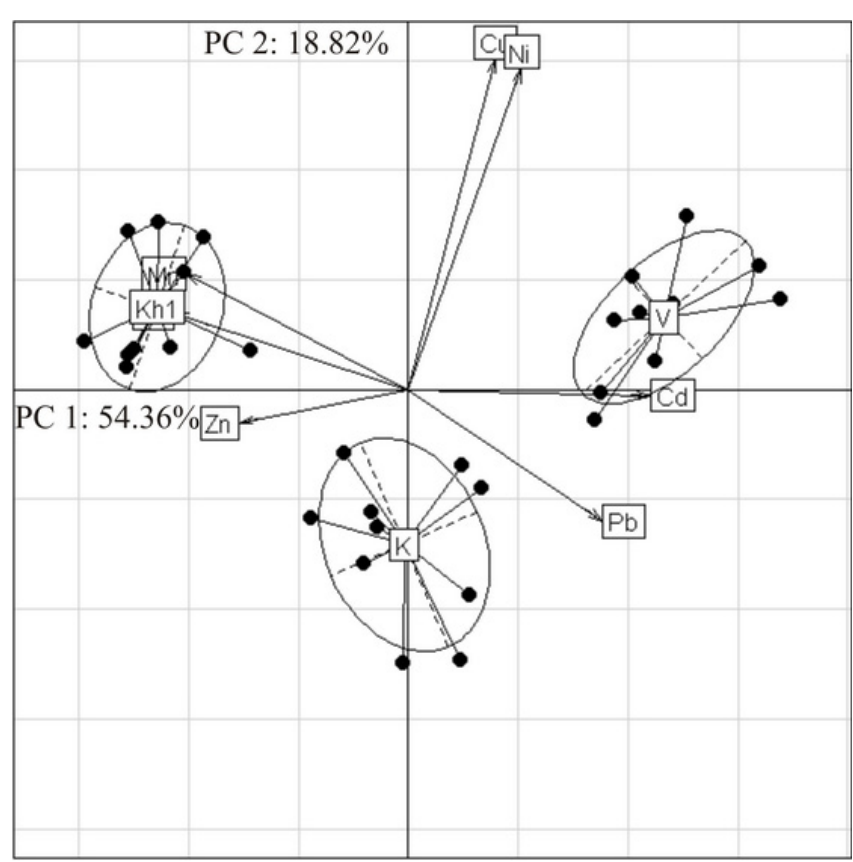

Рис. 2. Содержание тяжелых металлов в тканях $\mathrm{Hi}$ rudo verbana в пространстве главных компонент. Условные обозначения: Kh1 - Харьковская область 1, $\mathrm{V}$ - Волгоградская область, К - Краснодарский край; PC1, РC2 - оси главных компонент; \% - процент дисперсии данных, объясненных главной компонентой; стрелки отражают корреляцию главных компонент с исходными показателями; эллипсы представляют собой $95 \%$ доверительные области.

Fig. 2. The content of heavy metals in the tissues of medical leeches Hirudo verbana in the space of the main components. Designations: Kh1 - Kharkiv region 1, V - Volgograd region, K - Krasnodarsky Krai; PC1, PC2 - principal component axes, $\%$ - percentage of the data variance explained by the main components; arrows reflect the correlation of the main components with the initial indicators; ellipses are $95 \%$ confidence areas.

зана с температурным фактором (Моисеенко, 2009). Кроме того, ранее нами были получены данные о высоком содержании в тканях МП данной географической популяции свободных аминокислот, способствующих функционированию физиологических механизмов детоксикации и элиминации избыточного количества экотоксикантов в условиях повышенного содержания ТМ в окружающей среде (Chernaya et al., 2016).

Установлено, что пиявки $H$. verbana, независимо от места обитания, являются макроконцентраторами $\mathrm{Zn}, \mathrm{Cd}, \mathrm{Pb}\left(\mathrm{K}_{\mathrm{БH}}>2\right)$ и деконцентраторами $\mathrm{Mn}$ и $\mathrm{Fe}\left(\mathrm{K}_{\mathrm{БH}}<1\right)$ (табл. 5). Обнаружено, что особи $H$. verbana из волгоградской популяции проявляют не самую высокую кумулятивную активность к $\mathrm{Cu}, \mathrm{Ni}$ и $\mathrm{Pb}$, однако максимально накапливают в тканях токсичный Cd. Кадмий, в свою очередь, ингибирует депонирование необходимого количества 
эссенциального Zn, поскольку является его антагонистом. Наибольшая аккумуляционная активность к $\mathrm{Cu}, \mathrm{Mn}$ и $\mathrm{Ni}$, на фоне наименьшей - к $\mathrm{Cd}$ и $\mathrm{Pb}$, наблюдались у особей $H$. verbana из Харьковская области. Максимальная накопительная способность по отношению к $\mathrm{Zn}, \mathrm{Fe}$ и $\mathrm{Pb}$ и минимальная - к $\mathrm{Mn}$ и $\mathrm{Ni}$ характерна для краснодарских пиявок (табл. 5).

Корреляционный анализ показал, что концентрации $\mathrm{Zn}\left(\mathrm{r}_{\mathrm{s}}=-0.05 ; p=0.75\right)$ и $\mathrm{Mn}\left(\mathrm{r}_{\mathrm{s}}=0.07\right.$; $p=0.65)$ в тканях $H$. medicinalis европейских популяций не зависят от уровня их содержания в ДО. Это свидетельствует о наличии у пиявок механизмов регуляции процессов накопления этих эссенциальных металлов. Вместе с тем выявлена статистически значимая положительная корреляционная связь между уровнем содержания $\mathrm{Cu}, \mathrm{Fe}, \mathrm{Cd}, \mathrm{Pb}, \mathrm{Ni}$ в тканях $H$. medicinalis и их концентрациями в ДО $(p<0.01)$. Установлена очень высокая плотность связи для $\mathrm{Ni}$ и $\mathrm{Cd}\left(\mathrm{r}_{\mathrm{s}}=\right.$ 0.94 и $\mathrm{r}_{\mathrm{s}}=0.95$, соответственно; $\left.p=0.000\right)$, сильная - для $\mathrm{Pb}\left(\mathrm{r}_{\mathrm{s}}=0.86 ; p=0.000\right)$ и $\mathrm{Cu}\left(\mathrm{r}_{\mathrm{s}}=0.82\right.$ $p=0.000)$, средняя - для $\mathrm{Fe}\left(\mathrm{r}_{\mathrm{s}}=0.45 ; p=0.003\right)$.

Уровни содержания $\mathrm{Cu}, \mathrm{Fe}, \mathrm{Cd}, \mathrm{Pb}, \mathrm{Ni}$ в тканях $H$. verbana, как и у H. medicinalis, коррелируют с концентрациями этих ТМ в окружающей среде $(p<0.01)$. Для $\mathrm{Fe}$ и $\mathrm{Pb}$ связь между изучаемыми параметрами характеризуются как сопряженность средней силы $\left(\mathrm{r}_{\mathrm{s}}=0.54 ; p=0.002\right.$ и $\mathrm{r}_{\mathrm{s}}=$ $0.60 ; p=0.001$, соответственно). Высокая степень связи выявлена для $\mathrm{Cu}\left(\mathrm{r}_{\mathrm{s}}=0.70 ; p=0.000\right), \mathrm{Ni}\left(\mathrm{r}_{\mathrm{s}}\right.$ $=0.85 ; p=0.000)$ и $\mathrm{Cd}\left(\mathrm{r}_{\mathrm{s}}=0.97 ; p=0.000\right)$. Между тканевыми концентрациями $\mathrm{Zn}$ и $\mathrm{Mn}$ и их содержанием в ДО, как и в случае с H. medicinalis, не обнаружено статистически значимой связи $\left(\mathrm{r}_{\mathrm{s}}=\right.$ $0.01 ; p=0.95$ и $\mathrm{r}_{\mathrm{s}}=-0.01 ; p=0.98$, соответственно). Необходимо отметить, что аналогичный характер корреляционных связей был нами выявлен при исследовании сезонной аккумуляции ТМ пиявкой $H$. verbana (Chernaya et al., 2018).

\section{Заключение}

В результате проведенных исследований определен диапазон фоновых концентраций $\mathrm{TM} \mathrm{Cu}, \mathrm{Zn}, \mathrm{Fe}, \mathrm{Mn}, \mathrm{Cd}, \mathrm{Pb}, \mathrm{Ni}$ в тканях двух охраняемых видов МП $H$. medicinalis и $H$. verbana и в ДО мест их обитания, как в оптимальных климатогеографических условиях, так и на восточной и северной границах ареала. На фоне выявленной высокой географической вариабельности концентраций ТМ, анализ биоаккумуляционных способностей МП из водоемов различных природных зон позволил установить общие закономерности накопления эссенциальных и токсичных элементов в их организме. Показано, что, независимо от географической и биотопической приуроченности, оба вида являются макроконцентраторами $\mathrm{Zn}\left(\mathrm{K}_{\mathrm{БH}}>2\right)$ и деконцентраторами $\mathrm{Mn}$ и $\mathrm{Fe}\left(\mathrm{K}_{\text {Бн }}<1\right)$. Выявлена их высокая кумулятивная активность по отношению к $\mathrm{Cd}, \mathrm{Pb}$ и $\mathrm{Ni}$ в водных экосистемах промышленных регионов, свидетельствующая о биологической доступности экотоксикантов в этих условиях. Показано снижение биоаккумуляционной активности к ТМ у особей, обитающих в неблагоприятных климатических условиях на границах ареала. Установлена способность $H$. medicinalis и $H$. verbana peгулировать уровень эссенциальных металлов $\mathrm{Mn}$ и $\mathrm{Zn}$ в организме, тогда как содержание $\mathrm{Cu}, \mathrm{Fe}, \mathrm{Cd}, \mathrm{Pb}, \mathrm{Ni}$ определяется концентрацией этих элементов в ДО. Таким образом, географические особенности элементного состава тканей пиявок объективно отражают региональную специфику экологического состояния гидробиоценозов. Это указывает на возможность использования H. medicinalis и $H$. verbana в качестве биоиндикаторов при проведении мониторинга за загрязнением водных экосистем ТМ в черте их ареала.

Таблица 5. Показатели коэффициентов биологического накопления $\left(\mathrm{K}_{\mathrm{bH}}\right)$ тяжелых металлов у пиявок Hirudo medicinalis и $H$. verbana различных популяций

Table 5. Indicators of the coefficients of biological accumulation of heavy metals in leeches Hirudo medicinalis and H. verbana of various populations

\begin{tabular}{|c|c|c|c|c|c|c|c|}
\hline \multirow{2}{*}{ Регион исследования } & \multicolumn{7}{|c|}{ Тяжелые металлы } \\
\hline & $\mathrm{Cu}$ & $\mathrm{Zn}$ & $\mathrm{Mn}$ & $\mathrm{Fe}$ & $\mathrm{Cd}$ & $\mathrm{Pb}$ & $\mathrm{Ni}$ \\
\hline \multicolumn{8}{|c|}{ Hirudo medicinalis $(\mathrm{n}=50)$} \\
\hline Тамбовская область & 0.48 & 8.88 & 0.06 & 0.73 & 0.13 & 0.15 & 0.13 \\
\hline Харьковская область 1 & 2.88 & 11.13 & 0.30 & 0.41 & 2.57 & 2.16 & 1.28 \\
\hline Харьковская область 2 & 2.79 & 14.96 & 0.28 & 0.19 & 3.32 & 2.66 & 1.32 \\
\hline Луганская область & 4.42 & 9.10 & 0.65 & 0.38 & 7.94 & 3.40 & 2.95 \\
\hline Алтайский край & 0.67 & 8.73 & 0.02 & 0.08 & 3.24 & 0.91 & 0.73 \\
\hline \multicolumn{8}{|c|}{ Hirudo verbana $(\mathrm{n}=30)$} \\
\hline Харьковская область 1 & 2.46 & 12.61 & 0.29 & 0.44 & 2.77 & 2.26 & 1.43 \\
\hline Волгоградская область & 1.91 & 7.19 & 0.13 & 0.52 & 3.92 & 2.43 & 1.32 \\
\hline Краснодарский край & 2.16 & 16.07 & 0.07 & 0.72 & 3.22 & 2.59 & 0.97 \\
\hline
\end{tabular}


Полученные нами новые данные по фоновым концентрациям TM Cu, $\mathrm{Zn}, \mathrm{Fe}, \mathrm{Mn}, \mathrm{Ni}, \mathrm{Cd}, \mathrm{Pb}$ в тканях МП $H$. medicinalis и $H$. verbana различных географических популяций и в среде их обитания могут быть целенаправленно использованы для оптимизации мер по сохранению МП и восполнению их природных ресурсов, а также в качестве физиологической нормы для пиявок-производителей и их потомства в гирудокультуре.

\section{Благодарности}

Работа выполнена в рамках государственного задания Института экологии растений и животных УрО PAH, а также при частичной финансовой поддержке гранта Президиума РАН «Фундаментальные Науки Медицине» №12-П-4-1049.

\section{Литература}

Виноградов А.П. 1962. Среднее содержание химических элементов в главных типах изверженных пород земной коры // Геохимия. №7. С. 555-571.

Другов Ю.С., Родин А.А. 2009. Пробоподготовка в экологическом анализе: практическое руководство. 3-е изд. доп. и перераб. М.: БИНОМ. 855 с.

Еськов Е.К., Зубкова В.М., Белозубова Н.Ю., Болотов В.П. 2015. Содержание и миграция тяжелых металлов в компонентах экосистем Волгоградского водохранилища // Аграрная наука. №1. С. 14-16.

Каменев Ю., Каменев О. 2014. Вам поможет пиявка. Практическое руководство по гирудотерапии. СПб.: Весь. 192 с.

Ковалев С.И., Мальгин М.А., Сухоруков Ф.В., Маликова И.Н., Мельгунов С.В. 1993. Тяжелые металлы в почвах Алтайского края // Ядерные испытания, окружающая среда и здоровье населения Алтайского края. Барнаул: Изд-во Алт.ГУ, Т. 2. Кн. 1. С. 64-95.

Ковальчук Л.А., Черная Л.В. 2013. Элементный и аминокислотный спектр секрета слюнных желез и тканей медицинских пиявок. Значение для гирудотерапии // Вестник восстановительной медицины. №2. С. 36-39.

Красная книга Краснодарского края. Том 2: Животные. Краснодар: Центр развития ПТР Краснодарского края, 2007. $480 \mathrm{c.}$

Кустов С.Ю., Горбунова Ю.К., Вардо Л.Э. 2014. Оптимизация процесса выращивания медицинской пиявки (Hirudo medicinalis L.) в искусственных условиях // Труды Кубанского государственного аграрного университета. №48. С. 69-72.

Кустов С.Ю., Шаповалов М.И. 2012. Пиявка медицинская Hirudo medicinalis Linnaeus, 1758 // Красная книга Республики Адыгея. Редкие и находящиеся под угрозой исчезновения объекты животного и растительного мира. В 2-х ч. Ч. 1. Майкоп: «Качество». С. 41.

Лукин Е.И. 1976. Пиявки пресных и солоноватых водоемов. Т. 1. Л.: Наука. 484 с.

Моисеенко Т.И. 2009. Водная экотоксикология: теоретические и прикладные аспекты. М.: Наука. 400 с.
Никаноров А.М., Жулидов А.В., Покаржевский А.Д. 1993.Биомониторинг тяжелых металлов в пресноводных экосистемах. Л.: Гидрометеоиздат. 291 с.

Никонов Г.И., Титова Е.А., Лебедева А.О. 2015. Экстракт пиявок Hirudo medicinalis - биогенная субстанция для создания эффективных лекарственных средств // Экспериментальная и клиническая фармакология. Т. 78(2). C. 15-19. DOI: 10.30906/0869-2092-2015-78-2-15-19

Нохрина Е.С., Ковальчук Л.А., Черная Л.В. 2009. Динамика накопления тяжелых металлов в тканях медицинской пиявки Hirudo medicinalis L. в модельном эксперименте // Вестник Уральской медицинской академической науки. № 2(25). С. 145-146.

Рассадина Е.В., Романова Е.М. 2008. Особенности биологии, экологии, этологии и разведения медицинской пиявки в лабораторных условиях. Ульяновск: Изд-во УлГУ. 185 с.

Решетняк О.С., Брызгало В.А., Косменко Л.С. 2017. Многолетняя изменчивость содержания соединений кадмия и свинца в речных экосистемах России // География и природные ресурсы. №1. С. 71-80. DOI:10.21782/GIPR0206-1619-2017-1(71-80)

Рождественская T.А. 2003. Тяжелые металлы в почвах и растениях юго-западной части Алтайского края. Автореф. дис. ... канд. биол. наук. Барнаул. 24 с.

Романова Е.М., Климина О.М. 2010. Биоресурсы класса Hirudinea в зоне Среднего Поволжья: экологическая значимость и перспективы использования // Известия Самарского научного центра РАН. Т. 12(1). С. 208-211.

Степанова Н.Ю., Яковлев В.А., Латыпова В.3. 2007. Зообентос как индикатор экотоксикологической обстановки в Куйбышевском водохранилище // Вестник РУДН. Серия Экология и безопасность жизнедеятельности. №2. С. 50-57.

Флеров Б.А. 1989. Эколого-физиологические аспекты токсикологии пресноводных животных. Л.: Наука. 144 с.

Червона книга України. Тваринний світ. Київ: Глобалконсалтинг, 2009. 624 с.

Яковлев В.А. 2002. Воздействие тяжелых металлов на пресноводный зообентос: 1 бионакопление // Экологическая химия. Т. 11(1). С. 27-39.

Chernaya L.V., Kovalchuk L.A., Nokhrina E.S. 2016. Role of the tissue free amino acids in adaptation of medicinal leeches Hirudo medicinalis L., 1758 to extreme climatic conditions // Doklady Biological Sciences. Vol. 466(1). P. 42-44. DOI: 10.1134/S0012496616010129

Chernaya L.V., Kovalchuk L.A., Mikshevich N.V. 2018. Seasonal bioaccumulation of heavy metals by medicinal leech Hirudo verbana // Hydrobiological Journal. Vol. 54(5). P. 56-62. DOI: 10.1615/HydrobJ.v54.i5.60

Chessel D., Dufour A.B., Thioulouse J. 2004. The ade 4 package-I: One-table methods // R News. №4. P. 5-10.

CITES. 2017. Convention on the International Trade in Endangered Species of the Wild Fauna and Flora. Appendices I, II and III valid from 04 April 2017. Available from https://cites.org/eng/app/appendices.php

Elliot J.M., Kutschera U. 2011. Medicinal leeches: historical use, ecology, genetics and conservation // Freshwater Reviews. Vol. 4(1). P. 21-41. DOI: 10.1608/FRJ-4.1.417

Kovalchuk L.A., Mikshevich N.V., Chernaya L.V. 2017. Accumulation of heavy metals by small mammals the back- 
ground and polluted territories of the Urals // Vestnik Zoologii. Vol. 51(4). P. 325-334. DOI: 10.1515/vzoo-2017-0037

Lukashov D.V. 2015. Accumulation of heavy metals by pond snail Lymnaea stagnalis as index of pollution of small water bodies // Hydrobiological Journal. Vol. 51(4). P. 67-73. DOI: 10.1615/HydrobJ.v51.i4.80

Romanenko V.D., Liashenko A.V., Afanasyev S.A., ZorinaSakharova Y.Y. 2010. Biological indication of ecological status of the water bodies within Kiev city boundaries // Hydrobiological Journal. Vol. 46(4). P. 3-24. DOI: 10.1615/HydrobJ.v46.i4.10

Saglam N., Saunders R., Lang S.A., Shain D.H. 2016. A new species of Hirudo (Annelida: Hirudinidae): historical biogeography of Eurasian medicinal leeches. BMC Zoology. Vol. 1: 5. DOI: 10.1186/s40850-016-0002-x

Stumm W., Morgan J.J. 1996. Aquatic chemistry. N.Y.: Willey\&Sons. $1022 \mathrm{p}$.

Utevsky S., Zagmajster M., Atemasov A., Zinenko O., Utevska O., Utevsky A., Trontelj P. 2010. Distribution and status of medicinal leeches (genus Hirudo) in the Western Palaearctic: anthropogenic, ecological, or historical effects? // Aquatic Conservation: Marine and Freshwater Ecosystems. Vol. 20(2). P. 198-210. DOI: 10.1002/aqc.1071

Utevsky S., Zagmajster M., Trontelj P. 2014. Hirudo medicinalis // The IUCN Red List of Threatened Species 2014: e.T10190A21415816. Available frol http://dx.doi.org/10.2305/IUCN.UK.2014-1.RLTS. T10190A21415816.en

Yorkina N.V. 2016. Impact of technogenic pollution of urban environment on vitality indicators of urban biota (Mollusk fauna, soil mesofauna, epiphytic lichens) // Moscow University Biological Sciences Bulletin. Vol. 71(3). P. 177-183. DOI: 10.3103/S0096392516030044

\section{References}

Chernaya L.V., Kovalchuk L.A., Nokhrina E.S. 2016. Role of the tissue free amino acids in adaptation of medicinal leeches Hirudo medicinalis L., 1758 to extreme climatic conditions. Doklady Biological Sciences 466(1): 42-44. DOI: 10.1134/S0012496616010129

Chernaya L.V., Kovalchuk L.A., Mikshevich N.V. 2018. Seasonal bioaccumulation of heavy metals by medicinal leech Hirudo verbana. Hydrobiological Journal 54(5): 56-62. DOI: 10.1615/HydrobJ.v54.i5.60

Chessel D., Dufour A.B., Thioulouse J. 2004. The ade 4 package-I: One-table methods. $R$ News 4: 5-10.

CITES. 2017. Convention on the International Trade in Endangered Species of the Wild Fauna and Flora. Appendices I, II and III. Valid from 4 April 2017. Available from https://cites.org/eng/app/appendices.php

Drugov Yu.S., Rodin A.A. 2009. Sample preparation in environmental analysis: a practical guide. $3^{\text {rd }}$ ed. Moscow: BINOM. 855 p. [In Russian]

Elliot J.M., Kutschera U. 2011. Medicinal leeches: historical use, ecology, genetics and conservation. Freshwater Reviews 4(1): 21-41. DOI: 10.1608/FRJ-4.1.417

Flerov B.A. 1989. Ecological and physiological aspects of the toxicology of freshwater animals. Leningrad: Nauka. 144 p. [In Russian]
Kamenev Y., Kamenev O. 2014. A leech will help you. A practical guide to hirudotherapy. Saint-Petersburg: Ves'. 192 p. [In Russian]

Kovalchuk L.A., Chernaya L.V. 2013. Elemental and amino acid spectrum of secretions of the salivary glands and tissues of medical leeches. Significance for hirudotherapy. Bulletin of Restorative Medicine 2: 36-39. [In Russian]

Kovalchuk L.A., Mikshevich N.V., Chernaya L.V. 2017. Accumulation of heavy metals by small mammals the background and polluted territories of the Urals. Vestnik Zoologii 51(4): 325-334. DOI: 10.1515/vzoo-2017-0037

Kovalev S.I., Malgin M.A., Sukhorukov F.V., Malikova I.N., Melgunov S.V. 1993. Heavy metals in the soils of the Altai Territory. In: Nuclear tests, environment and health of the population of the Altaisky Krai. Barnaul: Publishing House of Altai State University. Vol. 2(1). P. 64-95. [In Russian]

Kustov S.Y., Gorbunova Y.K., Vardo L.E. 2014. Optimization of the process of growing medical leech (Hirudo medicinalis L.) in artificial conditions. Proceedings of the Kuban State Agrarian University 48: 69-72. [In Russian]

Kustov S.Y., Shapovalov M.I. 2012. Leech medical Hirudo medicinalis Linnaeus, 1758. In: Red Data Book of the Republic of Adygea. Rare and Endangered Objects of the Animal and Plant World. In 2 parts. Part 1. Maykop: «Kachestvo». P. 41. [In Russian]

Lukashov D.V. 2015. Accumulation of heavy metals by pond snail Lymnaea stagnalis as index of pollution of small water bodies. Hydrobiological Journal 51(4): 67-73. DOI: 10.1615/HydrobJ.v51.i4.80

Lukin E.I. 1976. Leeches of freshwater and brackish ponds. Vol. 1. Leningrad: Nauka. 484 p. [In Russian]

Moiseenko T.I. 2009. Aquatic ecotoxicology: theoretical and applied aspects. Moscow: Nauka. 400 p. [In Russian]

Nikanorov A.M., Zhulidov A.V., Pokarzhevsky A.D. 1993. Biomonitoring of heavy metals in freshwater ecosystems. Leningrad: Hydrometeoizdat. 291 p. [In Russian]

Nikonov G.I., Titova E.A., Lebedeva A.O. 2015. Extract of leeches Hirudo medicinalis - biogenic substance for the creation of effective medicines. Experimental and Clinical Pharmacology 78(2): 15-19. DOI: 10.30906/08692092-2015-78-2-15-19 [In Russian]

Nokhrina E.S., Kovalchuk L.A., Chernaya L.V. 2009. Dynamics of accumulation of heavy metals in the tissues of the medicinal leech Hirudo medicinalis L. in a model experiment. Bulletin of the Ural Medical Academic Science 2(25): 145-146. [In Russian]

Rassadina E.V., Romanova E.M. 2008. Features of biology, ecology, ethology and cultivation of medicinal leech in laboratory conditions. Ulyanovsk: Publishing House of Ulyanovsk State University. 185 p. [In Russian]

Red Data Book of the Krasnodarsky Krai. Vol. 2: Animals. Krasnodar: Centre of Development PTR of Krasnodarsky Krai, 2007. 480 p. [In Russian]

Red Data Book of Ukraine. Animals. Kyiv: Globalkonsalting, 2009. 624 p. [In Ukrainian]

Reshetnyak O.S., Bryzgalo V.A., Kosmenko L.S. 2017. Perennial variability in the content of cadmium and lead compounds in river ecosystems of Russia. Geography and Natural Resources 1: 71-80. DOI: 10.21782/ GIPR0206-1619-2017-1(71-80) [In Russian] 
Romanenko V.D., Liashenko A.V., Afanasyev S.A., ZorinaSakharova Y.Y. 2010. Biological indication of ecological status of the water bodies within Kiev city boundaries. Hydrobiological Journal 46(4): 3-24. DOI: 10.1615/HydrobJ.v46.i4.10

Romanova E.M., Klimina O.M. 2010. Biological resources of the Hirudinea class in the zone of the Middle Volga region: ecological significance and prospects for use. Proceedings of Samara Scientific Centre RAS 12(1): 208-211. [In Russian]

Rozhdestvenskaya T.A. 2003. Heavy metals in the soils and plants of the southwestern part of the Altaisky Krai. PhD Thesis Abstract. Barnaul. 24 p. [In Russian]

Saglam N., Saunders R., Lang S.A., Shain D.H. 2016. A new species of Hirudo (Annelida: Hirudinidae): historical biogeography of Eurasian medicinal leeches. BMC Zoology 1: 5. DOI: 10.1186/s40850-016-0002-x

Stepanova N.Y., Yakovlev V.A., Latypova V.Z. 2007. Zoobenthos as an indicator of the ecotoxicological situation in the Kuibyshev reservoir. RUDN Journal of Ecology and Life Safety 2: 50-57. [In Russian]

Stumm W., Morgan J.J. 1996. Aquatic chemistry. N.Y.: Willey \& Sons. 1022 p.

Utevsky S., Zagmajster M., Atemasov A., Zinenko O., Utevska O., Utevsky A., Trontelj P. 2010. Distribu- tion and status of medicinal leeches (genus Hirudo) in the Western Palaearctic: anthropogenic, ecological, or historical effects? Aquatic Conservation: Marine and Freshwater Ecosystems 20(2): 198-210. DOI: 10.1002 /aqc. 1071

Utevsky S., Zagmajster M., Trontelj P. 2014. Hirudo medicinalis. In: The IUCN Red List of Threatened Species 2014: e.T10190A21415816. Available from http://dx.doi.org/10.2305/IUCN.UK.2014-1.RLTS. T10190A21415816.en

Vinogradov A.P. 1962. The average content of chemical elements in the main types of igneous rocks of the earth's crust. Geochemistry 7: 555-571. [In Russian]

Yakovlev V.A. 2002. Effect of the amount of metals on freshwater zoobenthos: 1 bioavailability. Ecological Chemistry 11(1): 27-39. [In Russian]

Yeskov E.K., Zubkova V.M., Belozubova N.Y., Bolotov V.P. 2015. The content and migration of heavy metals in the components of the ecosystems of the Volgograd reservoir. Agrarian Science 1: 14-16. [In Russian]

Yorkina N.V. 2016. Impact of technogenic pollution of urban environment on vitality indicators of urban biota (Mollusk fauna, soil mesofauna, epiphytic lichens). Moscow University Biological Sciences Bulletin 71(3): 177-183. DOI: $10.3103 / \mathrm{S} 0096392516030044$

\title{
GEOGRAPHICAL VARIABILITY OF HEAVY METAL CONCENTRATIONS IN TISSUES OF MEDICAL LEECHES (HIRUDO MEDICINALIS, HIRUDO VERBANA) AND IN BOTTOM DEPOSIT
}

\author{
Liudmila V. Chernaya ${ }^{1, *}$, Liudmila A. Kovalchuk ${ }^{1}$, Nikolay V. Mikshevich ${ }^{2}$ \\ ${ }^{1}$ Institute of Ecology of Plants and Animals Ural Branch of RAS, Russia; \\ ${ }^{2}$ Ural State Pedagogical University, Russia \\ *e-mail:kovalchuk@ipae.uran.ru
}

\begin{abstract}
We present new data of the comparison of the geographical variability of heavy metal concentrations $(\mathrm{Cu}, \mathrm{Zn}$, $\mathrm{Mn}, \mathrm{Fe}, \mathrm{Cd}, \mathrm{Pb}, \mathrm{Ni}$ ) in tissues of medical leeches (Hirudo medicinalis, Hirudo verbana) and in bottom deposit from places of their inhabitation in various regions of Russia and Ukraine. The geographical factor was found to have a significant impact on the elemental status of medical leeches and bottom sediments. It was shown that, irrespective of geographic and biotopic timing, both types of medicinal leeches are macroconcentrator $\mathrm{Zn}$ and deconcentrator $\mathrm{Mn}$ and Fe. A high cumulative activity of $H$. medicinalis and $H$. verbana in relation to ecotoxicants $\mathrm{Cd}, \mathrm{Pb}$ and $\mathrm{Ni}$ in aquatic ecosystems of industrial regions was revealed. A decrease in bioaccumulation activity towards heavy metals in specimens of medical leeches living in adverse climatic conditions on the northern and eastern borders of the range is shown. The ability of leeches $H$. medicinalis and $H$. verbana to regulate the level of essential metals $\mathrm{Mn}$ and $\mathrm{Zn}$ in the body is established, while the content of $\mathrm{Cu}, \mathrm{Fe}, \mathrm{Cd}, \mathrm{Pb}$, $\mathrm{Ni}$ is determined by the concentration of these elements in the habitat (bottom sediments). A high variability of the studied parameters and the general laws of bioaccumulation activity of leeches in relation to heavy metals are caused of significant correlation with climatic and geographical features of the studied regions, and a degree of anthropogenically modified territories. It is shown that the microelemental status of leeches as a whole objectively reflects regional specificity of the ecological conditions of hydrobiocoenosises. Thus, the performed investigation can be used in monitoring actions for preservation of water resources and protection of natural biological resources of the hirudofauna.
\end{abstract}

Key words: aquatic ecosystems, bioaccumulation, ecotoxicants, essential metals, protected species 